\title{
An inverse effect of UCS intensity upon partially reinforced eyelid conditioning'
}

ROBERT BOICE AND CAROL BOICE

MICHIGAN STATE UNIVERSITY

Two groups of 20 Ss were run in a classical eyelid conditioning experiment with one group receiving a UCS intensity of $50 \mathrm{~mm}$ and the other a $100 \mathrm{~mm}$ intensity. Acquisition data showed superior performance in the group receiving the weaker UCS, a direct reversal from that found in CRF eyelid conditioning. Analysis of CRs following reinforced and nonreinforced trials indicated that although both groups performed at a significantly higher level following reinforced trials, there was no interaction between the two kinds of CRs and UCS intensity.

In classical eyelid conditioning the differential effect of UCS intensity under partial reinforcement appears to develop following reinforced, as opposed to nonreinforced, trials, with performance being higher following reinforced trials (Spence \& Trapold, 1961; Runquist, 1963). Runquist (1963) suggests that this performance level difference may be due to the generation of inhibition by nonreinforced trials with the omission of a strong UCS producing greater inhibition than omission of a weaker UCS. If so, it could be predicted that performance level following nonreinforced trials would be poorer with a strong UCS than with a weak UCS. Two studies of PR in eyelid conditioning (Gormezano et al, 1962; Runquist, 1963), both of which omitted rather than delayed the UCS on nonreinforced trials, have reported the incidental finding that weaker UCS intensities tended to produce a higher level of performance than stronger intensities.

This experiment was designed to test the idea that partially reinforced eyelid conditioning with UCS omitted on nonreinforced trials might show a higher level of conditioning with the weaker of two UCSs and that this effect would be most evident following nonreinforced trials.

\section{Method}

Twelve male and eight female undergraduates from the University of Alberta comprised each of the two groups of $20 \mathrm{Ss}$ in this study. After being given neutral instructions, each S served for one $40 \mathrm{~min}$. session of 120 eyelid conditioning trials. The intertrial intervals were irregularly spaced at 15,20 , or $25 \mathrm{sec}$. The two groups differed as to UCS intensities which displaced 50 or $100 \mathrm{~mm}$ of mercury. All Ss received the same randomized pattern of 50 per cent reinforced and 50 per cent nonreinforced (no UCS) trials, with the restriction on randomness being that each block of 20 trials contained 10 reinforced and 10 nonreinforced trials. No ready signal was used.

The conditioning laboratory is described in detail elsewhere (Runquist \& Muir, 1965). Essentially, two Ss sat in isolated booths each facing a white wall from which protruded a black box containing a $3 \times 5$ in. ground glass face. The CS was an increase in the brightness of this glass face to a value of 12.0 as measured with a Gossen-Luna-6 light meter. Room illumination provided a background level of 14.2 from the white wall. The UCS for both groups was a puff of compressed nitrogen of $100 \mathrm{msec}$. duration delivered $500 \mathrm{msec}$. after CS onset. All stimuli were timed with Hunter Timers and programmed with punch tape. The recording system consisted of the Mechanical-electrical system now in common use. A CR was defined as a $1 \mathrm{~mm}$ deflection between 150-500 msec. after CS onset. Results

Curves showing the per cent CRs on trials following reinforced and nonreinforced trials for both UCS intensities are presented in Fig. 1. These data are generally consistent with the findings of Runquist (1963) in that performance is higher following reinforced trials for both groups, and also greater under the weaker UCS conditions. An analysis of variance revealed that both of these main effects were significant: $F=4.80, d f=1 / 38$, $\mathrm{p}<.05$ for UCS intensity and $\mathrm{F}=4.96, \mathrm{df}=1 / 418, \mathrm{p}<.05$ for reinforcement. The interactions were not significant nor were any interactions of any variables over trials, with all Fs being less than 1.00 .

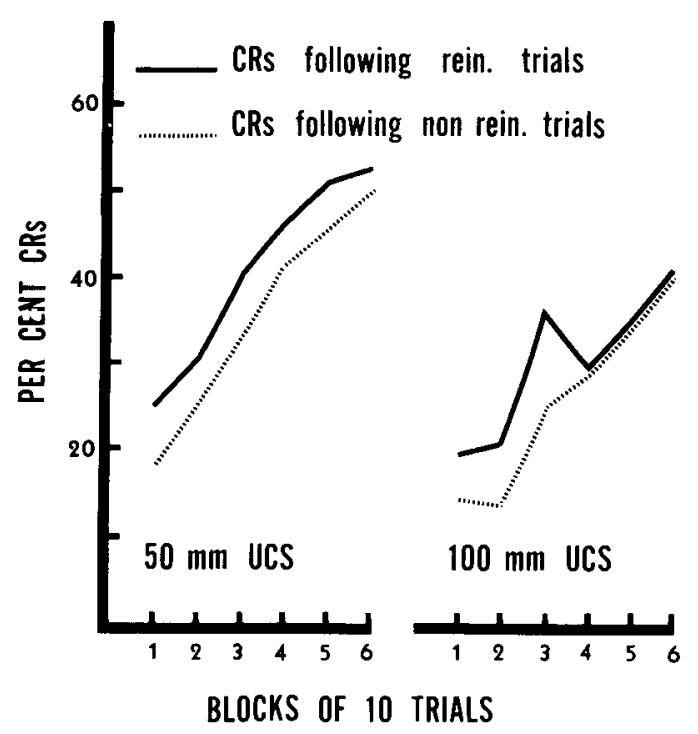

Fig. 1. Mean percentage of CRs in blocks of 10 trials. 


\section{Discussion}

The primary finding of this study was that under partial reinforcement conditions a weak UCS $(50 \mathrm{~mm})$ led to a higher level of eyelid conditioning than did a strong $(100 \mathrm{~mm})$ UCS (final mean level of CRs $=\mathbf{5 2}$ per cent vs. 41 per cent respectively). This is a reversal from the relationship of UCS intensity and performance level in CRF eyelid conditioning (Spence, 1956). It should be pointed out that these findings are limited to a PR situation in which UCSs are omitted rather than delayed on nonreinforced trials and no ready signal is used. For this reason these results are not comparable to those of Ross \& Spence (1960).

The lack of an interaction with CRs following reinforced vs. nonreinforced trials goes against the expectation (Runquist, 1963) that greater decrement develops on a nonreinforced trial as a function of UCS intensity. Thus it appears, in this study, that the effect of UCS intensity on partially reinforced eyelid conditioning is differential only across intensities and not between types of trials.

\section{References}

Gormezano, I., Moore, J. W., \& Deaux, E. Yoked comparisons of classical and avoidance eyelid conditioning under three UCS intensities. J. exp. Psychol., 1962, 64, 551-552.

Ross, L. E., \& Spence, K. W. Eyelid conditioning performance under partial reinforcement as a function of UCS intensity. $J$. exp. Psychol., 1960, 59, 379-382.

Runquist, W. N. Performance in eyelid conditioning following changes in reinforcement schedule. J. exp. Psychol., 1963, 65, 617-618.

Runquist, W. N., \& Muir, W. R. Intrasession decrements in the performance of the classically conditioned eyelid reflex. J. exp. Psychol., 1965, 70, 520-525.

Spence, K. W., \& Trapold, M. A. Performance in eyelid conditioning as a function of reinforcement schedules and changes in them. Proc. Nat. Acad. Sci., Washington, D. C., 1961, 47, 1860-1868.

Spence, K. W. Behavior theory and conditioning. New Haven: Yale University Press, 1956.

\section{Note}

1. The authors wish to thank Dr. W. N. Runquist of the University of Alberta for the use of his facilities and for his helpful advice, and Allan Jones who secured the subjects for the study. The research was supported by NIH Grant HD-0047-02. 